\title{
REPENSANDO A LICENCIATURA: A GRADUAÇÃO EM FILOSOFIA E A FORMAÇÃO DOCENTE PARA O NÍVEL MÉDIO
}

\author{
Walter Luiz Mauch, Licenciando em Filosofia /UFPR e NESEF - Curitiba, Brasil
}

\section{Resumo}

As graduações em Filosofia se direcionam no sentido de preparar os alunos para o mestrado ou carreira eclesiástica, pouco tendo a oferecer aos discentes que desejam formação que os habilite a exercer a contento as funções de professor no nível médio. Presa aos ditames estruturalistas, se por um lado tiveram o mérito de formar leitores capacitados na exegese dos textos clássicos; por outro dissociaram o pensar filosófico dos problemas nacionais e do pensar crítico. Neste sentido, este artigo se propõe a analisar a estrutura curricular e o método pedagógico adotado nos cursos de graduação em Filosofia da região metropolitana de Curitiba, privilegiando a atenção ao conteúdo e forma como disciplinas do bacharelado são trabalhadas e apreendidas. Por fim, sugerimos novas formas de estruturação dos cursos de Filosofia e apontamos caminhos alternativos de abordagem o texto filosófico.

Palavras-chave: Bacharelado em Filosofia; Metodologia de Ensino; Currículo Filosofia.

\section{RETHINKING THE PHILOSOPHY DEGREE AND THE HIGH SCHOOL TEACHER TRAINING}

\begin{abstract}
The graduations in Philosophy are directed towards preparing students for the master's or ecclesiastical career, having little to offer students who want training to enable them to perform satisfactorily the duties of a teacher at the secondary level. Caught in the standards structuralisms, on the one hand had the merit of educating readers in exegesis of classical texts, on the other disassociated the philosophical thinking of national problems and critical thinking. Thus, this article aims to analyze the curriculum and teaching method adopted in undergraduate courses in Philosophy of Curitiba metropolitan region, focusing attention to the content and how the disciplines are worked baccalaureate and seized. Finally, we suggest new ways of structuring courses in Philosophy and show alternative ways to address the philosophical text.
\end{abstract}

Key words: Bachelor of Philosophy, Teaching Methodology, Curriculum Philosophy.

O que caracteriza a divisão do trabalho no interior da sociedade moderna é que ela cria as especialidades, as espécies e, com elas, o idiotismo de ofício.

Karl Marx - Miséria da Filosofia

Introdução

Com a volta da disciplina de Filosofia no Ensino Médio no Estado do Paraná, as licenciaturas em Filosofia adentraram em uma nova etapa que exigirá um repensar da estrutura curricular e das metodologias, visando oferecer uma real preparação para os profissionais que pretendem exercer a docência de nível médio. Com necessidades distintas do processo de formação 
de especialistas na pós-graduação, a licenciatura em Filosofia deve ter seus conteúdos pedagógicos construídos de forma dialética e crítica, valorizando o múltiplo, a contradição e o antagonismo das diversas correntes de pensamento e dos seus atores.

Nesta direção as "Diretrizes Curriculares da Educação Básica - Filosofia”, elaboradas pela Secretaria de Estado da Educação do Paraná, propõem que o ensino de Filosofia no nível médio não deve ser simples transposição das metodologias adotadas nas graduações e pós-graduações em Filosofia; onde o decifrar da lógica interna dos textos filosóficos, descontextualizados do momento histórico e das contradições sociais, culmina no entendimento de que a 'Filosofia não precisa servir para nada'. Em sentido oposto, as Diretrizes Curriculares sugerem que os sujeitos e o local devem ser levados em consideração, abrindo espaço para que o saber filosófico torne-se novamente vivo, nos seguintes termos:

Identifica-se o local onde se pensa e fala a partir do resgate histórico da disciplina e da militância por sua inclusão e permanência na escola. Ensinar Filosofia no Ensino Médio, no Paraná, no Brasil, na América Latina, não é o mesmo que ensiná-la em outro lugar. Isso exige do professor claro posicionamento em relação aos sujeitos desse ensino e das questões históricas atuais que lhes são colocadas como cidadãos de um país. Nesse sentido, é preciso levar em conta as contradições próprias da nossa sociedade que é, ao mesmo tempo, capitalista e dependente, rica e explorada, consciente e alienada. (SECRETARIA DE EDUCAÇÃO DO ESTADO DO PARANÁ, 2008, p. 48).

No contexto em questão, o estudo do texto filosófico transforma-se de fria especialização em dominar conceitos numa fonte rica de conteúdos estruturantes, sugerindo aos alunos novas formas de compreender uma realidade que lhe é normalmente adversa. É este fio humanista que o professor deverá buscar, fazendo a conexão entre o domínio do saber técnico e as demandas por um saber questionador, neste aspecto:

Tal reflexão enseja analisar a função do professor de Filosofia no Ensino Médio, que consiste, basicamente, em pensar de maneira filosófica para construir espaços de problematização compartilhados com os estudantes, a fim de articular os problemas da vida atual com as respostas e formulações da história da Filosofia e com a criação de conceitos. (SECRETARIA DE EDUCAÇÃO DO ESTADO DO PARANÁ, 2008, p. 53).

A partir do eixo da docência no nível médio, elaboramos uma análise dos cursos de graduação em Filosofia da Universidade Federal do Paraná, Pontifícia Universidade Católica do Paraná, Faculdade Bagozzi e FAE - Centro Universitário. A pesquisa contou com entrevistas de professores e alunos, questionários e análise de documentos. Enfocamos cada curso de forma separada, salientando a estrutura curricular, as metodologias de ensino e o público alvo a que se 
destinam. Abordamos o processo de implantação da Filosofia universitária no Brasil, com a criação da USP em 1934, e a fratura que o surgimento da modernidade burguesa causou na Filosofia profissional acadêmica. A partir da análise, diagnóstico e crítica das graduações, detalhamos as possíveis medidas a serem adotadas com o fito de aproximar a licenciatura em Filosofia da docência no nível básico e médio.

\section{De costas para o mundo}

O filósofo do tipo sartreano ou voltaireano não existe mais. Feneceu a idéia da Filosofia como disciplina intelectual independe e relevante para o conjunto da sociedade, capaz de intervir nos grandes temas da sociedade contemporânea. Sem qualquer culpa ou remorso, passamos o facho da crítica e análise social para economistas e sociólogos, reassumindo a antiga função dos monges copistas medievais: a guarda e exegese dos textos clássicos de Filosofia.

O fim da Filosofia como pensamento vivo e o nascimento da Filosofia profissional, consagrando que "o único assunto da Filosofia é a própria Filosofia”, aconteceu, segundo Paulo E. Arantes (1996. p. 30 - 33), pelas mãos de Immanuel Kant e seu sistema transcendental. Nos termos de Hegel, citado por Arantes, havia no sistema kantiano "o perigo da irrelevância vindoura", ao se preocupar com aquilo que seria anterior a todo conhecimento. A Filosofia transcendental, buscando conhecimento sem conhecimento, seria um "círculo vicioso", um "saber negativo" que causaria um “dano irreparável à verdadeira inteligência filosófica". Desta forma, o projeto da crítica kantiana não poderia ser executado "de costas para o mundo, sob pena de esterilizá-lo". Uma visão complementar sugeriria que a Filosofia kantiana seria, na realidade, uma retomada da Filosofia de corte estritamente acadêmico, seguindo um continuum que remontaria à Idade Média, com os Padres da Igreja. Os escolásticos já traziam em seu bojo as principais características da futura Filosofia acadêmica: a vida restrita ao ambiente universitário, a exegese dos textos clássicos e a introspecção.

O continuum ideológico da escolástica para o idealismo Kantiano se origina nas similaridades das condições históricas objetivas da sociedade feudal e da alemã do final do século XVIII. Nesta época a Inglaterra se lançava à Revolução Industrial, sustentada teoricamente pelo Materialismo e Empirismo; na França os revolucionários abraçavam a Filosofia Iluminista, unindo o Materialismo Empirista à acidez da crítica social e a prática política radical. Em situação contrária, na região ao leste do Reno a situação era, em larga medida, caracterizada por relações sociais feudais ou semifeudais. Dominavam o cenário político germânico dezenas de reinos, ducados e cidades livres, isolados e autônomos, governados por uma aristocracia retrógrada. A economia era basicamente agrária tendendo para auto-suficiência; a industrialização era incipiente e 
de caráter artesanal. Neste ambiente se debatia a sociedade culta alemã, medrosa do radicalismo político francês, receosa da inevitável modernização capitalista que se anunciava e saudosista de uma idílica Idade Média de pequenos camponeses. É esta contradição social, de uma Alemanha feudal que se quer moderna e conservadora (MOORE, 1983), que criou a ruptura entre Filosofia e práxis e fez renascer a filosofia profissional. O Materialismo francês se voltava para o mundo, preocupado com a política, a economia e as ciências naturais. Já o idealismo kantiano se fechou sobre si mesmo, tornando-se seu próprio assunto e nas universidades encontrou o lócus privilegiado para florescer.

Desta forma, não ocorreu um 'fim da Filosofia' como argumenta Paulo Arantes, unicamente aconteceu que a Filosofia 'de frente para o mundo' foi relegada a um segundo plano pela academia - o Materialismo, por exemplo, foi taxado de vulgar - e os herdeiros do sistema kantiano - Aristóteles da filosofia analítica, Husserl, Heidegger, Wittgenstein e Kripke, entre outros - formaram o mainstream da filosofia universitária ocidental.

\section{O modelo uspiano}

Com a derrota da oligarquia paulista na Intentona de 32, o campo de luta contra o Varguismo passa a ser o ideológico e a USP, criada em 1934, será instituída com o objetivo de formar uma elite de intelectuais e técnicos que deverão levar adiante o projeto de modernização conservadora da burguesia paulista. Produto deste projeto classista, a USP espelhará as contradições que as nações de capitalismo tardio devem enfrentar no processo de formação nacional. Surgida como colônia extrativista, a dinâmica social, econômica e política brasileira segue o padrão do desenvolvimento desigual e combinado do capitalismo dependente. Os modelos buscados serão sempre os das nações hegemônicas, num afã contínuo de copiar uma estrutura que se constituiu em um tempo e história própria. O Iluminismo, a democracia liberal e o capitalismo são formas longamente gestadas no processo econômico e na dinâmica contraditória das classes sociais européias. Surgida tardiamente, a burguesia brasileira e sua fração mais vigorosa, a paulista, aparecem em uma fase do capitalismo em que as classes dominantes dos países centrais já haviam se lançado ao imperialismo, buscando mercados mundiais para suas manufaturas. No Brasil, a burguesia ainda engatinhava no processo de industrialização e o setor dinâmico da economia era a exportação de café, que até poucas décadas era organizado com base na mão de obra escrava.

Nestas condições, a importação de modelos exógenos não permite que se construa instituições que alcancem vôos próprios e atinjam a totalidade de suas potencialidades. Estando sempre um passo atrás da matriz dos países centrais, criamos a ilusão de um projeto autônomo e 
moderno de nação, quando, na realidade, perpetuamos uma dependência econômica, sociocultural e política, neste sentido:

Por conseguinte, o referido padrão de modernização produz uma alocação errada de fatores materiais e humanos, alimenta forma de crescimento ou e desenvolvimento substancialmente deformadas e estabelece as bases para a perene continuidade do "progresso importado" Os agentes que tomam as "decisões modernizadoras" individual ou coletivamente (e internos ou externos) supõem que reproduzem o modelo original de economia, sociedade ou cultura. Na verdade, o processo tende a criar economias, sociedades e culturas homólogas aos modelos originais mas para funcionar sob seu controle indireto, sob sua influência e para o seu proveito. Isso acarreta uma diferenciação do modelo simulado, que passa a ser homólogo em tudo, menos na capacidade de funcionamento, de crescimento e de desenvolvimento relativamente autônomo, auto-sustentado e autopropelido. (FERNANDES, 1981, p. 85)

$\mathrm{Na}$ formação cultural nacional a Filosofia universitária não deixa de ser o caso mais emblemático da falta de autonomia intelectual e da assimilação aos padrões metropolitanos de pensamento. Congelada no tempo, a academia manteve os mesmos temas e formas de leitura da data de sua instauração no Brasil nos 30. Longe da equivocada pretensão de se criar uma Filosofia de caráter autóctone, pois a natureza humana e o valor trabalho não são características próprias do Brasil ou da América Latina, mas da humanidade em geral e dos diversos modos de produção dominantes, nas diversas épocas históricas; o caminho para uma filosofia de caráter nacional deve seguir o mesmo trajeto das demais áreas das ciências humanas, que a partir dos pensadores clássicos criou um caldo de cultura eminentemente nacional. Na Sociologia, por exemplo, é unânime o reconhecimento dos avanços que a ciência social brasileira produziu para o entendimento da "questão Brasil". É impossível pensar os grandes dilemas nacionais sem lembrar os nomes de Octavio Ianni, Florestan Fernandes, Fernando Henrique Cardoso, Gilberto Freyre, Darci Ribeiro, entre outros. Sem descuidar da leitura dos clássicos, base imprescindível para ulterior desenvolvimento, a sociologia brasileira criou uma feição própria, de caráter nacional e voltado para discussão de grandes temas.

\section{As licenciaturas}

\section{UFPR}

O curso de graduação da UFPR se reorganizou, em meados dos anos 90, como espelho do modelo uspiano de como deveria funcionar um bacharelado em Filosofia. Além do molde uspiano, 65\% dos professores também são oriundos da pós-graduação desta instituição, o que reforça a ligação com um projeto de curso que remonta ao início do século passado. 


\section{Estrutura curricular}

O currículo atual está vigente desde 1999. O aluno, normalmente, leva de 4,5 a 5 anos para cursá-lo. São 1.560 h de disciplinas obrigatórias e 720 h de disciplinas optativas. Em média as optativas tem a duração $60 \mathrm{~h} /$ semestre, o que gera 12 disciplinas. As obrigatórias de formação em Filosofia são: 'Introdução a Filosofia I'; 'Filosofia Geral I'; 'Seminário de Leitura Análise e Produção de Textos Filosóficos I e II'; 'Ética I'; 'Filosofia Política I'; 'História da Filosofia Moderna I'; 'Lógica I'; 'História da Filosofia Antiga I'; 'Filosofia da Ciência I'; 'História da Filosofia Contemporânea I'; 'Estética I'; 'Teoria do Conhecimento I'; 'História da Filosofia Clássica Alemã I'; 'Teoria das Ciências Humanas I' e 'Filosofia da Linguagem I'. Aparentemente, pelo título das disciplinas obrigatórias, existiria a intenção de abranger as principais correntes da Filosofia ocidental. No entanto, pesquisando alunos ingressos nos anos de 2006 e 2007, encontramos outra realidade, com a preponderância da filosofia moderna e analítica.

Tabulamos os autores conforme o número de vezes que foram abordados durante o curso (Tabela 01). Por exemplo, se uma disciplina abrangeu apenas um autor, este terá valor 1,0 . Se fossem dois autores, o peso será 0,5 para cada um. Desta forma, Kant com peso 128,60 foi 75 vezes mais abordado que Epicuro. A primeira conclusão é de que não existe homogeneidade nas análises dos autores. A filosofia moderna com Kant, Hume, Berkeley, Descartes e a filosofia analítica com Aristóteles e Kripke, perfazem 51\% do total de autores estudados. Habermas, Lukács, Weber, Benjamin, Adorno e Horkheimer foram abordados juntos e apenas na disciplina de 'Teoria das Ciências Humanas I'. Por outro lado, Kant freqüentemente aparece como tema único em 'Estética I' e 'História da Filosofia Clássica Alemã I'. Os pensadores brasileiros e latino-americanos foram marginalmente enfocados com Paulo E. Arantes e Antonio Candido. 
Tabela 01 - Proporção em que os autores foram abordados.

\begin{tabular}{|c|c|c|c|c|c|}
\hline Autor & $\mathrm{N}^{\mathrm{o}}$ & Abordagens & Autor & $\mathrm{N}^{\mathrm{o}}$ & Abordagens \\
\hline EPICURO & 1 & 1,70 & NIETZSCHE & 22 & 8,30 \\
\hline BACON & 2 & 2,50 & POPPER & 23 & 10,00 \\
\hline TOMÁS DE AQUINO & 3 & 2,50 & AGOSTINHO & 24 & 10,00 \\
\hline WITTGEINSTEIN & 4 & 2,50 & ROUSSEAU & 25 & 10,30 \\
\hline HABERMAS & 5 & 2,80 & MAQUIAVEL & 26 & 11,10 \\
\hline POPE & 6 & 4,20 & HEIDEGGER & 27 & 13,30 \\
\hline VOLTAIRE & 7 & 4,20 & HUSSERL & 28 & 13,30 \\
\hline WALTER BENJAMIN & 8 & 4,20 & SCHILINK & 29 & 13,30 \\
\hline ANTONIO CANDIDO & 9 & 5,00 & MARCUSE & 30 & 14,20 \\
\hline PASCAL & 10 & 5,00 & FREGE & 31 & 14,90 \\
\hline PAULO ARANTES & 11 & 5,00 & KUHN & 32 & 15,00 \\
\hline LUKÁCS & 12 & 5,40 & HOBBES & 33 & 16,90 \\
\hline WEBER & 13 & 6,20 & PLATÃO & 34 & 20,00 \\
\hline FOUCAULT & 14 & 7,00 & LOCKE & 35 & 20,30 \\
\hline HANNAH ARENDT & 15 & 7,00 & SCHOPENHAUER & 36 & 30,00 \\
\hline HEGEL & 16 & 7,30 & BERKELEY & 37 & 35,80 \\
\hline CARNAP & 17 & 7,50 & KRIPKE & 38 & 37,40 \\
\hline LEIBNIZ & 18 & 7,50 & MARX & 39 & 43,50 \\
\hline ADORNO & 19 & 8,20 & HUME & 40 & 74,10 \\
\hline HORKHEIMER & 20 & 8,20 & DESCARTES & 41 & 81,60 \\
\hline \multirow[t]{2}{*}{ NEWTON } & 21 & 8,30 & ARISTÓTELES & 42 & 82,00 \\
\hline & & & KANT & 43 & 128,60 \\
\hline
\end{tabular}

Fonte: Elaborado pelo autor

O resultado da tabulação dos dados segundo os conteúdos exprime a predominância do Idealismo Alemão $^{12}-\mathbf{2 4 \%}$, seguido da Filosofia analítica/ciência ${ }^{13}-\mathbf{1 9 \%}$ e do Empirismo $\mathbf{- 1 6 \%}$. Por fim, figura o Racionalismo - 12\%. Também, neste caso, não existe um equilíbrio entre os grandes temas da Filosofia, predominando uns em detrimento de outros.

As $720 \mathrm{~h}$ de disciplinas optativas são, na realidade, extensões das disciplinas obrigatórias do núcleo formador em Filosofia. O aluno irá ter mais do mesmo, ou seja, serão os mesmos autores e método das obrigatórias, não contribuindo para ampliar o estreito leque de pensadores abordados. A possibilidade que o graduando tem de realizar $120 \mathrm{~h}$ de disciplinas eletivas, das $720 \mathrm{~h}$ optativas, em outros departamentos é quase que exclusivamente utilizada com as 'línguas estrangeiras instrumentais'; sintoma dos ditames do estruturalismo que impõem que a melhor leitura possível do texto clássico será na língua original. Outro aspecto a ser salientado é que, ao contrário dos demais cursos das ciências humanas na UFPR, o currículo do curso prima pela total ausência de qualquer

\footnotetext{
${ }^{12}$ Tendo em vista que Karl Marx é estudado sob a ótica do jovem Marx e da visão lukacsiana de "História e Consciência de Classe", as abordagens deste autor foram separadas $2 / 3$ para a o Idealismo Alemão e 1/3 para a Teoria Crítica.

${ }^{13}$ Aristóteles é estudado, de forma predominante, como teórico da Filosofia analítica. Dividimos, então, o número de abordagens em 2/3 para a Filosofia analítica e 1/3 para a Filosofia Antiga.
} 
outra disciplina que não seja relacionada diretamente com a formação técnica em Filosofia.

O novo currículo, a ser implementado a partir do $2^{\circ}$ semestre de 2011 separa a licenciatura do bacharelado, passando a carga horária da licenciatura de $2.280 \mathrm{~h}$ para $2.870 \mathrm{~h}$. No currículo de 1999 o núcleo de formação filosófica em Filosofia soma 1.800 h. No currículo a ser implementado a partir de 2011, o núcleo de formação em Filosofia somará 1.875 h (formação introdutória geral 240 h; formação intermediária - 1.275 h; disciplinas optativas filosóficas - 360 h). Ou seja, a nova licenciatura terá a mesma carga horária do atual bacharelado e as disciplinas técnicas serão praticamente as mesmas, sendo excluído o 'Seminário de Leitura, Análise e Produção de Textos Filosóficos II', que será substituída pela 'História da Filosofia Patrística e Medieval I'.

Quanto ao conteúdo das disciplinas técnicas filosóficas, não haverá qualquer adaptação das matérias filosóficas às necessidades da nova licenciatura. Continuarão sendo lecionados na mesma forma e conteúdo que são no atual bacharelado, consoante Vieira (2011). O novo "Projeto Pedagógico" do curso de Filosofia da UFPR não traz inovações neste aspecto, mantendo como objetivo do bacharelado e, conseqüentemente, das matérias específicas de formação filosófica: "promover o estímulo à pesquisa, direcionando sua atuação aos programas de pós-graduação, em especial ao programa de mestrado do Departamento de Filosofia, e à futura atuação do bacharel no magistério superior" (UFPR, 2011).

\section{O método}

O método pedagógico e de estudo na graduação é baseado na análise estruturalista do texto clássico de Filosofia. As aulas são expositivas, abrangendo, normalmente, a leitura e comentário de um texto em sala de aula ou a explanação de algum tema específico de um pensador. É corriqueiro um capítulo de determinada obra ser objeto de estudo durante todo um semestre, ou, de uns poucos parágrafos em uma aula (cada aula tem usualmente a duração de três horas). Dá-se muita atenção às traduções, sendo corriqueiro o professor discutir longamente, em sala de aula, as alternativas de tradução de um termo. Além desta excessiva preocupação com o específico em detrimento do abrangente, a ausência completa de contextualização aproxima o método pedagógico e de estudo ao das ciências exatas. Um professor de Química ou Física estaria pedagogicamente bem ambientado na Filosofia universitária brasileira.

O próprio uso do termo 'análise do texto clássico' já aponta que as formulações filosóficas são obras engessadas pela tradição e pelo passar dos tempos e que, como obras de arte antiga, devem permanecer intocadas para deleite do espectador. Divergente das demais áreas das ciências humanas, que consideram seus autores como bases teóricas para posterior problematização, na 
Filosofia acadêmica o texto clássico é um fim em si mesmo, ou seja, o estudo de um autor começa e termina dentro do seu próprio texto.

O método estruturalista desembarcou no Brasil junto com a missão francesa que criou a USP anos 30. Tal foi o sucesso da leitura estruturalista na academia que ao tornar-se moda em meados dos anos 60, o estruturalismo pouco impacto trouxe ao ambiente filosófico brasileiro, já afeito havia décadas ao método exegético. Das diversas correntes que compõem o estruturalismo, na Filosofia universitária o Positivismo predominará e se caracterizará: valorização do empírico (neste caso o texto clássico), adoção do paradigma das ciências naturais como modelo para as ciências humanas e crença na neutralidade do pesquisador frente ao objeto pesquisado, livrando a interpretação do texto teórico de qualquer juízo de valor.

O artigo "Tempo histórico e tempo lógico na interpretação dos sistemas filosóficos" de Vitor Goldschmidt (1963) é considerado na academia o modelo que norteará estudo do texto filosófico. Segundo Goldschmidt parece que haveria duas formas de se estudar um sistema: interrogar sobre sua verdade ou sobre sua gênese. No primeiro método, chamado de "dogmático" (sic) por Goldschmidt, o pesquisador procura a intenção do autor, buscando a verdade de um sistema, com a possibilitando da crítica e a refutação. No segundo, nomeado "genético", o historiador deverá considerar o ambiente econômico e políticos no qual foi criado o sistema, as características biográficas e fisiológicas do autor. No método "dogmático" ao buscar a verdade o pesquisador iria descortinar as contradições internas dos sistemas filosóficos e a anarquia das diferentes doutrinas. No método "genético" procuraria explicar e entender as contradições dos diferentes sistemas.

Goldschmidt descarta a análise "dogmática" e "genética" e formula um método que, segundo ele, seria "científico e filosófico". O sistema "científico e filosófico" deverá ser considerado em sua atemporalidade, separado do tempo histórico, dos fatos econômicos e políticos, da história da ciência e da história das idéias. A biografia do autor também não seria relevante, já que a biografia estaria contaminada pelos pontos de vistas do biógrafo e seria "um tempo vivido (...) não filosófico". O método deveria se preocupar com a estrutura, buscando as causas de uma doutrina dentro da própria doutrina construída pelo autor. Desta forma Goldschmidt sustenta que a obra filosófica deve ser produto de metodologia, que não histórica mas lógica:

Os movimentos do pensamento filosófico estão inscritos na estrutura da obra, nada mais sendo esta estrutura, inversamente, que as articulações do método em ato; mais exatamente: é uma mesma estrutura, que se constrói ao longo da progressão metódica e que, uma vez terminada, define a arquitetura da obra. Ora, falar em movimento e progressão é, a não ser que fique em metáforas, supor um tempo, e um tempo estritamente metodológico ou, guardando para o termo sua etimologia, um tempo lógico. (GOLDSCHMIDT, 1963, p. 2). 


\section{FAE - Centro Universitário}

A FAE é uma organização ligada aos Frades Franciscanos, tendo como mantenedora a Associação Franciscana de Ensino Senhor Bom Jesus (AFESBJ). O curso de licenciatura em Filosofia da FAE foi reconhecido pelo MEC em 2008 e já se encontra adaptado às novas diretrizes curriculares, oferecendo 40 vagas anualmente.

A maior parte dos alunos está ligada a seminários e conventos, seguido de profissionais liberais, como advogados e psicólogos, e por último de interessados na docência de nível médio (FERRANDIN, 2011), . A estrutura curricular ${ }^{14}$, ao contrário do curso da UFPR, busca uma formação menos especializada, mais focada nos aspectos gerais de um tema do que especificamente nas idéias de um autor. Também fica claro que o currículo tem afinidade com o seu principal publico alvo: os religiosos. Disciplinas como 'Antropologia filosófica I e II', 'Filosofia da Religião' e 'História do Pensamento Franciscano', por exemplo, tem sua temática diretamente relacionada com o problema religioso. As disciplinas do currículo também apontam para a formação estrita, ante a ausência de qualquer outra disciplina que não relacionada com a Filosofia. A bibliografia de cada disciplina é dividida em 'básica' e 'complementar', com a preponderância de textos introdutórios, histórias da Filosofia e manuais sobre o texto clássico de Filosofia.

\section{Faculdade Bagozzi}

A faculdade Bagozzi tem como mantenedora a Congregação dos Oblatos de São José. O curso é reconhecido pelo MEC desde 2006 e oferece 150 vagas anualmente. Da mesma forma que a FAE, o curso de Filosofia da Faculdade Bagozzi tem forte presença de religiosos no seu corpo discente (dos formandos de 2009, no turno matutino, 7 eram religiosos e 5 leigos ${ }^{15}$ ). O currículo é similar ao da FAE, com a inclusão de ‘Grego Clássico' e ‘Latim' como disciplinas obrigatórias. Ao contrário da UFPR, onde predomina o particular sobre o geral, na Faculdade Bagozzi cada

\footnotetext{
${ }^{14}$ Psicologia Geral (36 h) Teoria do Conhecimento (72 h). $3^{\circ}$ Semestre:Antropologia Filosófica II (72 h); Didática (72 h); Filosofia da Arte (72 h); História da Filosofia Medieval (36h); Filosofia da Educação (72 h); Problemas Metafísicos (36 h). $4^{\circ}$ Semestre: História do Pensamento Franciscano (72 h); Filosofia da Religião (36 h); História da Filosofia Moderna I(72 h); Métodos de Pesquisaem Filosofia (72 h); Prática de Ensino I (Estágio Supervisionado em Filosofia) (132 h); Problema Metafísicos II (72 h); Políticas Públicas de Educação (36 h). $5^{\circ}$ Semestre: Ética Filosófica I (36 h); Filosofia da Linguagem (72 h); Filosofia Política (72 h); História da Filosofia Moderna II (36 h); História da Filosofia Contemporânea I (36 h); Monografia em Filosofia I (92 h); Prática de Ensino II (Estágio Supervisionado em Filosofia) (134 h); Seminários de Filosofia I (36 h). $6^{\circ}$ Semestre: Estudo do Homem Contemporâneo (72 h); Ética Filosófica II (36 h); Filosofia da Ciência (72 h); História da Filosofia Contemporânea II (72 h); Monografia em Filosofia II (92 h); Prática e Ensino III (Estágio Supervisionado em Filosofia Seminários de Filosofia II) (134 h); Introdução à Língua Brasileira de Sinais - LIBRAS (36 h); Atividades Acadêmicas -Científico- Culturais (200 h).

15 Entrevista com ex-aluna, dia 25 jun. 2011.
} 
disciplina busca dar ao aluno uma visão abrangente do pensamento de vários autores, sem se ater a parágrafos ou capítulos de uma obra. Por exemplo, na disciplina de 'Teoria do Conhecimento', estuda-se George Berkeley, David Hume, Tomás de Aquino e Francis Bacon. Na UFPR em 'Teoria do Conhecimento I', normalmente, enfoca-se Hume apenas. A preocupação com uma visão mais geral também aparece nos trabalhos e avaliações do curso. Tomaremos duas questões como exemplo: na faculdade Bagozzi a questão era: "Analise a concepção de juízo estético na terceira crítica de Kant”. Na UFPR: "Comente o conceito de Sublime, a partir da definição dada por Kant na seção 115 da Crítica do juízo: “ele é um objeto (da natureza), cuja representação determina o ânimo a imaginar a inacessibilidade da natureza como representação de idéias"”".

\section{PUC Curitiba}

O curso de Filosofia da PUC Curitiba inscreve-se em dois modelos de abordagem. No turno da manhã a maior parte dos alunos é vinculada a instituições religiosas, no período noturno predomina o público laico. O currículo curso reflete esta característica, com disciplinas de caráter mais religioso ('Cultura Religiosa' e 'Antropologia Filosófica I e II') e de integração social na comunidade ('Projeto Comunitário'). Destoando do enfoque especialista, apenas com disciplinas da área filosófica, o currículo oferece como obrigatórias a 'História Geral I, II, III e IV' e 'História do Brasil I e II'.

Se pelo aspecto curricular existe o interesse em ofertar uma formação menos estreita, por outro, seguindo o padrão uspiano, é incentivada a especialização filosófica tendo em vista os programas de pós-graduação. Na PUC a filosofia contemporânea - Heidegger e Nietzsche - tem predominância sobre as demais áreas (OLIVEIRA, 2011). $\mathrm{Na}$ esteira deste processo de afunilamento teórico, os alunos, a partir do segundo ano, devem obrigatoriamente participar de um projeto de pesquisa. Ou seja, na graduação, onde o aluno deveria ter contato com as diversas correntes do pensamento filosófico, parte-se desde o início da formação intelectual para um processo de especialização em um tema e/ou autor, comprometendo amplamente o já reduzido espaço que o discente tem para se dedicar as demais áreas de saber e outras atividades acadêmicas.

\section{Repensando a licenciatura}

Os novos cursos de licenciatura em Filosofia implantados e em implantação, caso da UFPR, estruturaram suas grades curriculares tendo por base as tradicionais disciplinas técnicas de Filosofia, agregando a estas novas matérias de cunho pedagógico. A questão é que o grande entrave na formação dos professores para o nível médio é justamente as matérias específicas de Filosofia, 
sobre as quais não ouve qualquer tipo reformulação tendo em vista as especificidades da licenciatura. Como detalhado acima, não existe maior cuidado com a preparação dos graduandos no pensar conceitos e sistemas filosóficos de forma crítica e de 'frente para o mundo'. Mantiveram-se, em maior ou menor grau, os autores do mainstream acadêmico, as disciplinas de caráter especificamente técnico e a leitura estruturalista do texto, tendo em vista um futuro mestrado ou carreira eclesiástica, neste sentido:

O professor especializa-se em um autor, obra ou sistema filosófico e transforma seu objeto de estudo individual no conteúdo que transmite nas aulas de graduação. O graduando, por sua vez, é convidado a especializar-se na mesma linha do mestre [...] Este graduando - iniciando e futuro bacharel - dificilmente opta pela licenciatura e quando isso acontece há uma tendência de transferir este modelo espólio do positivismo disputado no sistema acadêmico - para sua prática, servindo como suporte para seu posicionamento posterior em relação à disciplina e aos alunos, como se estes devessem recortar conteúdos filosóficos específicos, especializando-se nos mesmos. (HORN apud HORN; MENDES, 2008, p. 3).

Tal é a condição da formação dos filósofos que formam filósofos, olham as licenciaturas como o parente pobre, como uma sub-habilitação (PALÁCIOS apud HORN; MENDES, 2008, p. 3). Enquanto os conteúdos das disciplinas pedagógicas continuarem sendo tratadas como complemento - apêndice e as matérias de formação filosófica como bloco distinto, impermeável aos aspectos pedagógicos, a tarefa formativa estará fadada ao fracasso. (HORN apud HORN; MENDES, 2008, p. 3).

Para retirar a Filosofia acadêmica de seu nicho exclusivista e capacitar os filósofos para intervirem nos grandes debates nacionais, a grade curricular do curso deve contemplar matérias outras que não apenas as de caráter técnico-filosófico. Não é possível imaginar a contextualização/problematização de conceitos filosóficos sem a coparticipação das demais áreas do conhecimento humano.

A formação exclusivista do bacharelado, focando apenas matérias de cunho filosófico não predomina mais na pátria mãe do modelo uspiano. Na França a licenciatura em Filosofia se expandiu, permitindo que o estudante de graduação opte, além da formação restrita ao campo filosófico, pela formação em Ciência Política (Sociologia), Direito e Letras, como oferecido pela Université Paris I (2011). A transposição deste modelo de dupla licenciatura para a realidade brasileira esbarraria na precariedade do ensino básico no Brasil. Enquanto um aluno oriundo da escola pública francesa tem condições de cursar duas licenciaturas em três anos de curso, no Brasil são necessários no mínimo cinco anos para uma satisfatória formação universitária.

A idéia de um ciclo básico de matérias que permitiriam ampliar a formação do futuro filósofo e professor já existe concretamente na graduação em Filosofia da Universidad de Buenos 
Aires (UBA, 2011). Um ciclo básico de dois anos ${ }^{16}$, ofertando matérias optativas e obrigatórias nas áreas de Economia Política, Letras, Sociologia, Antropologia, História, Ciências Exatas e Naturais forneceria ao aluno o necessário embasamento para o estudo do texto filosófico e a flexibilidade intelectual exigida de um profissional que deve responder as mais diversas áreas do conhecimento, que vão desde as questões éticas até a crítica cultural. Nos três anos seguintes de curso, o aluno optaria por áreas específicas da Filosofia, além das disciplinas de licenciatura, como também ocorre na UBA.

A vantagem em se permitir que o discente faça um recorte entre as diversas do áreas saber filosófico é possibilitar que a escolha se faça mais em função futuro interesse profissional do aluno e menos no interesse dos professores ou das instituições de ensino. Um graduando, por exemplo, que deseja exercer o magistério em nível médio poderia optar por Filosofia Política e Ética, em detrimento de Filosofia Analítica, área esta que não faz parte dos conteúdos estruturantes indicados pelas Diretrizes Curriculares da Secretaria Estadual de Educação do Paraná

Logicamente que apenas a ampliação no rol de disciplinas ofertadas não irá garantir uma maior aproximação com as necessidades do magistério de nível médio, se as matérias de formação filosófica continuarem a serem ministradas dentro dos ditamos da análise estruturalista de texto. É claro que não existe ensino de Filosofia sem auxílio dos textos clássicos, mas a academia sustenta dogmaticamente que o único método de ensino é o positivista, acreditando na possibilidade da neutralidade científica no estudo do texto filosófico. Honestidade intelectual não é sinônimo de neutralidade, o professor de Filosofia deve ter como meta explicitar conceitos de forma rigorosa, com apoio da mais avalizada bibliografia sobre o tema; mas isto não é impossibilidade para que sistemas filosóficos sejam comparados entre si, criticados e contextualizados historicamente.

Preparar o aluno, futuro professor, para contextualização e problematização do texto filosófico é tarefa que deve ocorrer durante a graduação. Não é crível que um licenciado, treinado durante cinco anos dentro dos ditames da exegese positivista, consiga, em um passe de mágica, incitar os alunos do nível médio para o pensar crítico. O pensar crítico requer determinadas precondições que a especialização acadêmica torna cada vez mais inacessível. Pressupõe-se que um bacharel ou licenciado saiba esgrimir conceitos e sustentar teses em um debate, manipulando sistemas teóricos com desenvoltura. No entanto, as normas da Filosofia acadêmica apontam para o sentido inverso. Por exemplo, na UFPR, no curso de 'Estética I' em 2009, aulas de três horas foram utilizadas na leitura de alguns parágrafos e no semestre inteiro discutiu-se apenas os conceitos Objekt e Gegenstand da Estética Transcendental. Ou, ainda, na disciplina de 'Historia da Filosofia

16 Diversos cursos na UFPR adotam o ciclo básico. Na Agronomia, por exemplo, durante os dois primeiros anos da graduação o aluno terá aula em de química, física, botânica, entomologia, entre outros, oferecidos pelos respectivos departamentos. 
Antiga I', abordou-se somente um autor, Aristóteles, e da extensa obra do Estagirita, apenas dois capítulos da Metafísica sob o enfoque da filosofia analítica. Assim, o aluno torna-se especialista em capítulos da obra de um filósofo, rompendo a lógica interna dos sistemas, condição sine qua non para o domínio de uma teoria e sua utilização como ferramenta intelectual. O foco em capítulos ou parágrafos é mais adequado às disciplinas optativas ou cursos de pós-graduação, não em disciplinas introdutória como o caso de 'Estética I' e 'Filosofia Antiga I'. Nestas disciplinas, por exemplo, a estética kantiana deveria ser apenas um dos pontos abordados, conjuntamente com Platão, Hegel e Lukács. Em 'Filosofia Antiga I' deveria ser oferecida uma visão abrangente sobre as principais ideais de Platão e Aristóteles.

\section{Conclusão}

Nos quatro cursos de licenciatura em Filosofia analisados; UFPR, PUC, Bagozzi e FAE, a preparação do aluno de graduação para a docência no nível básico e médio não é considerada a principal prioridade ou divide prioridades com outras carreiras que não a docência. A licenciatura na FAE e Bagozzi compartilha a formação do professor com a instrução para a carreira eclesiástica. Na UFPR a licenciatura em Filosofia é apêndice do bacharelado, pois os esforços são no sentido do treinar os graduandos na análise dos textos clássicos, visando mestrados e doutorados. Na PUC, a licenciatura divide atenção com a carreira eclesiástica e acadêmica.

A prática pedagógica, os autores e sistemas filosóficos, a bibliografia, o currículo, a formação dos professores e a intenção destes e da instituição de ensino devem ser orientadas no sentido de que o principal objetivo seja a formação para a docência de nível médio. As especificidades requeridas no exercício do magistério não aceitam compartilhamento de objetivos; a licenciatura deve ser primeira prioridade e não uma irmã pobre do bacharelado. Como demonstrado, a Filosofia universitária no Brasil seguiu um rumo que não é complementar à docência de nível médio, mas antagônico. São formas de compreender um mesmo campo de saber que devem seguir rumos próprios; dialogando, mas não convivendo sob a mesma estrutura organizacional. A Filosofia acadêmica escolheu voltar o olhar para si mesma - tendência que se exacerba com a expansão da filosofia analítica nos meios universitários brasileiros - a licenciatura, pelo contrário, deve capturar para si os sistemas filosóficos que estão de 'frente para o mundo', voltando a compartilhar saberes com as demais áreas do pensamento humano; fornecendo aos alunos e futuros docentes da educação básica as ferramentas intelectuais necessárias ao pensamento autônomo e independente das determinações ideológicas impostas pela necessidade da valorização do capital.

Desta forma, a licenciatura em Filosofia deve ser estruturada em um curso de graduação 
voltado para e unicamente à formação de professores para o nível básico e médio; separando-se do bacharelado tecnicista e da preparação para a carreira eclesiástica. Não haveria nenhuma suposta cisão entre ensino e pesquisa, pois ao se prender unicamente ao texto clássico, a pesquisa na área filosófica no Brasil apenas reproduz o que já foi feito em outros épocas e lugares. Fato surpreendente seria, por exemplo, detectar em Kant um aspecto sobre o qual já não exista trabalho publicado a nível mundial; autor sobre o qual se debruça com afinco a academia há mais de 200 anos. Ao invés de repetir aquilo que já foi publicado, a licenciatura em Filosofia deveria criar suas próprias especializações, mestrados e doutorados, preparando professores e pesquisadores que saibam manejar e aplicar conceitos filosóficos aos problemas concretos da sociedade, com o firme propósito de voltar à origem da Filosofia: a formação integral do cidadão - a Paidéia.

\section{Referências}

ARANTES, P. E. O fio da meada: Uma conversa e quatro entrevistas sobre Filosofia e vida nacional. São Paulo: Paz e Terra, 1996.

Um departamento françês de ultramar: Estudos sobre a formação da cultura filosófica uspiana (Uma experiência nos anos 60). São Paulo: Paz e Terra, 1994.

FERNANDES, F. Capitalismo dependente e classes sociais na América Latina. 3. ed. Rio de Janeiro: Zahar Editores, 1981.

FERRANDIN, J. A licenciatura em Filosofia na FAE. Curitiba: abr. 2011. Entrevista concedida a W. L. Mauch.

GIROUX, H. Escola crítica e política cultural. São Paulo: Cortez Editora, 1987.

GOLDSCHMIDT, V. Tempo histório e tempo lógico na interpretação dos sistemas filosóficos: A religião de Platão. São Paulo: Difusão Européia do Livro, 1963, p. 139-147. Disponível em: http://www.consciencia.org/tempo-historico-e-tempo-logico-na-interpretacao-dos-sistemasfilosoficos-victor-goldschmidt. Acesso em 23/08/2011.

GOMES, R. Crítica da razão tupiniquim. Disponível em:

http://www.iphi.org.br/sites/Filosofia brasil/Roberto Gomes - Critica da Razao Tupiniquim.pdf. Acesso em 24/08/2011.

HORN, G. B.; MENDES, A. A. P. Ensino de Filosofia e produção docente. In:Congresso Internacional de Filosofia: debate de idéias e cidadania. Caxias do Sul, 2008.

JAEGER, W. Paidéia: a formação do homem grego. São Paulo: Martins Fontes, 2003.

LUKÁCS, G. História e consciência de Classe: Estudos sobre a dialética marxista. São Paulo: Martins Fontes, 2003.

MARX, K. A ideologia Alemã. São Paulo: Boitempo Editorial, 2007.

. Miséria da Filosofia. Lisboa: Editorial Estampa, 1978.

MOORE, B. As origens sociais da ditadura e da democracia: senhores e camponeses na construção do mundo moderno. 1. ed. São Paulo: Martins Fontes, 1983.

OLIVEIRA, J. R. A licenciatura em Filosofia na PUC PR. Curitiba: abr. 2011. Entrevista concedida a W. L. Mauch. 
PARANÁ.SEED. Diretrizes Curriculares da Educação Básica - Filosofia. Curitiba, 2008.

UNIVERSIDAD DE BUENOS AIRES. Licenciatura em Filosofía. Disponível em: http://www.uba.ar/download/academicos/o_academica/carreras/lic-Filosofia.pdf. Acesso em 23/08/2011.

UNIVERSIDADE FEDERAL DO PARANÁ. Projeto pedagógico. Disponível em: http://www.Filosofia.ufpr.br/?page=grad projeto. Acesso em 23/08/2011.

UNIVERSITÉ PARIS I. Apresentação da licenciatura em Filosofia. Disponível em: http://www.univ-paris1.fr/ufr/ufr10/. Acesso em 23/08/2011.

VIEIRA NETO, P. A Licenciatura e o bacharelado na UFPR. Curitiba: jun. 2011. Entrevista concedida a W. L. Mauch. 